\title{
The relationship of psychological trauma with trichotillomania and skin picking
}

\author{
This article was published in the following Dove Press journal: \\ Neuropsychiatric Disease and Treatment \\ 15 May 2015 \\ Number of times this article has been viewed
}

\author{
Eylem Özten' \\ Gökben Hızlı Sayar' \\ Gül Eryılmaz' \\ Gaye Kağan² \\ Sibel Ișı $\mathbf{k}^{3}$ \\ Oğuz Karamustafalıoğlu ${ }^{4}$
}

'Neuropsychiatry Health, Practice, and Research Center, Üsküdar University, ${ }^{2}$ Istanbul Neuropsychiatry Hospital, Üsküdar University, ${ }^{3}$ Turkish Red Crescent Altıntepe Medical Center, ${ }^{4}$ Department of Psychology, Faculty of Human and Social Sciences, Üsküdar University, Istanbul, Turkey

Correspondence: Eylem Özten NPİstanbul Hastanesi Alemdağ Caddessi, Siteyolu Sokak No 27, Ümraniye, İstanbul, Turkey

Tel +902166330633

Fax +902I 66341250

Email eylem.ozten@uskudar.edu.tr; eylemozten@yahoo.com
Objective: Interactions between psychological, biological and environmental factors are important in development of trichotillomania and skin picking. The aim of this study is to determine the relationship of traumatic life events, symptoms of post-traumatic stress disorder and dissociation in patients with diagnoses of trichotillomania and skin picking disorder.

Methods: The study included patients who was diagnosed with trichotillomania $(n=23)$ or skin picking disorder $(n=44)$, and healthy controls $(n=37)$. Beck Depression Inventory, Traumatic Stress Symptoms Scale and Dissociative Experiences Scale were administered. All groups checked a list of traumatic life events to determine the exposed traumatic events.

Results: There was no statistical significance between three groups in terms of Dissociative Experiences Scale scores $(P=0.07)$. But Beck Depression Inventory and Traumatic Stress Symptoms Scale scores of trichotillomania and skin picking groups were significantly higher than the control group. Subjects with a diagnosis of trichotillomania and skin picking reported statistically significantly higher numbers of traumatic and negative events in childhood compared to healthy subjects.

Conclusion: We can conclude that trauma may play a role in development of both trichotillomania and skin picking. Increased duration of trichotillomania or skin picking was correlated with decreased presence of post-traumatic stress symptoms. The reason for the negatively correlation of severity of post-traumatic stress symptoms and self-harming behavior may be speculated as developing trichotillomania or skin picking symptoms helps the patient to cope with intrusive thoughts related to trauma. Future longitudinal research must focus on whether trauma and post-traumatic stress or trichotillomania and skin picking precede the development of mental disorder.

Keywords: psychological trauma, trichotillomania, skin picking

\section{Introduction}

Trichotillomania (TTM) has been first defined in the 19th century as a syndrome that leads to noticeable hair loss by pulling out one's own hair. The hair pulling behavior is accompanied by a feeling of distress, and it leads to gratification or relief while pulling the hair. ${ }^{1}$ TTM is mainly involved in pulling out hair, and less frequently pulling out hairs from different parts of the body. ${ }^{2}$ The bodily area of pulling out hair is reported as $75 \%$ scalp hair, $53 \%$ eyelashes, $42 \%$ eyebrows, $10 \%$ beard, and $17 \%$ pubic area, and it is seen in more than one area with increasing age. ${ }^{3}$ TTM was classified under the title of "Impulse Control Disorders Not Classified Elsewhere" in Diagnostic and Statistical Manual of Mental Disorders, fourth edition, text revision (DSM-IV-R) and as "Habit and Impulse Disorder" in International Classification of Diseases, tenth revision (ICD-10). ${ }^{4}$ Although there are many assumptions about TTM, the etiology is not clear. ${ }^{5}$ While discussing TTM to be classified within the obsessive spectrum before Diagnostic and Statistical Manual of Mental Disorders, fifth edition (DSM-5), 
it has been reported that, in a person suffering from mental trauma, obsessive-compulsive disorder (OCD) symptoms might have been developed in order to cope with anxiety and intrusive thoughts associated with trauma. ${ }^{6}$

People with TTM might shift their focus from traumatic material to pulling out hair in order to reduce their anxiety. Owing to phenomenological and neurobiological similarities with OCD, several researchers have suggested that TTM might be better conceptualized as an obsessive-compulsive spectrum disorder, and it has been classified under obsessive-compulsive and related disorders title in DSM-5. ${ }^{7,8}$ Skin picking (SP) is an irresistible scratching and picking urge to the extent that skin lesions are caused by the patients due to excessive excoriation. Frequency of SP is reported to be $2 \%$ in patients admitted to a dermatology clinic, ${ }^{9} 4 \%$ in university students, ${ }^{10}$ and $5.4 \%$ in a nonclinical population. ${ }^{11}$ SP disorder is mostly accompanied by major depressive disorder and OCD. It is reported to be more frequent in women. Although SP has been recommended to be classified in impulse control disorders not otherwise specified in DSM-IV-TR, ${ }^{12}$ it was classified in obsessive-compulsive disorder and related disorders section in DSM-5. ${ }^{13}$

1. TTM diagnostic criteria are as follows according to DSM-5 ${ }^{13}$ :

a. Trichotillomania

i. recurrent pulling out of one's hair, resulting in hair loss;

ii. repeated attempts to decrease or stop hair pulling;

iii. the hair pulling causes clinically significant distress or impairment in social, occupational, or other important areas of functioning;

iv. the hair pulling or hair loss is not attributable to another medical condition (eg, a dermatological condition); and

$\mathrm{v}$. the hair pulling is not better explained by the symptoms of another mental disorder (eg, attempts to improve a perceived defect or flaw in appearance in body dysmorphic disorder).

2. SP diagnostic criteria are as follows according to DSM- $5^{13}$ :

a. SP disorder

i. recurrent SP resulting in skin lesion;

ii. repeated attempts to decrease or stop SP;

iii. the SP causes clinically significant distress or impairment in social, occupational, or other important areas of functioning; and

iv. the SP is not attributable to the physiological effects of a substance (eg, cocaine) or another medical condition.
The SP is not better explained by symptoms of another mental disorder (eg, delusions or tactile hallucinations in a psychotic disorder, attempts to improve a perceived defect or flaw in appearance in body dysmorphic disorder, stereotypies in stereotypic movement disorder, or intention to harm oneself in nonsuicidal self-injury).

Personality allegedly plays a role in the development of TTM and SP. ${ }^{14}$ Emotionality and emotional regulation difficulties, reward dependence and harm avoidance, have been reported among the personality traits in both disorders. ${ }^{15}$ Environmental factors, boredom, and lack of stimulation have been reported being possible triggers of hair pulling and SP episodes. ${ }^{14}$ TTM development has been considered to be a behavioral response to stress in order to reduce anxiety or to cope with anxiety. ${ }^{16,17}$ Various researchers reported the high frequency of traumatic events in the past history of patients with SP ${ }^{18,19}$ and $\mathrm{TTM}^{6,20}$ compared to healthy population.

In a study on young women, it has been reported that history of sexual abuse and rape in childhood was one of the predictors of SP, but not of TTM. ${ }^{21}$ Although trauma history is not reported in all patients with a diagnosis of TTM, childhood trauma is reported to be higher when compared to patients without any psychiatric diagnoses. ${ }^{20,22}$ Exposure to interpersonal violence is reported to be high during the initial phase of the TTM. ${ }^{20}$ Approximately $76 \%$ of patients with TTM have been found to have a history of at least one traumatic life event, and $19 \%$ have a lifetime diagnosis of post-traumatic stress disorder (PTSD). ${ }^{23}$ Results of research suggest that in patients with TTM, PTSD prevalence was found to be higher than the general population but lower than psychiatric sample. ${ }^{23}$ It is interesting that the number of pulled hairs and duration of hair pulling are negatively correlated with the severity of comorbid PTSD in TTM patients. ${ }^{6}$ Regarding the relation between TTT, $\mathrm{SP}$, and dissociative symptoms, it has been reported that onethird of SP patients have a feeling of trance or a feeling of mesmerized during SP. ${ }^{24,25}$ In a study, $21.3 \%$ of the patients with TTM had reported depersonalization during pulling out hair. ${ }^{26}$ Despite the high frequency of dissociative symptoms in TTM and SP, the number of studies is limited.

This study was aimed to search for the relationship of psychological trauma with TTM and SP. A secondary aim was to investigate the presence of dissociative symptoms with TTM or SP.

\section{Methods}

The study included 67 outpatients who had been admitted to the Neuropsychiatry Istanbul Hospital between January 2012 and March 2014 and who were diagnosed with TTM $(n=23)$ or SP disorder $(n=44)$ according to the DSM-IV-TR 
criteria. Also, age- and sex-matched healthy controls $(n=37)$ were included in the study. The normal controls were selected from hospital staff who were compatible with TTM and SP groups in terms of age, sex, and education. Clinical interviews were conducted by three psychiatrists. Demographic and clinical data of the subjects were recorded. Necessary information was given about self-reported list of traumatic events, Traumatic Stress Symptoms Scale (TSSS), the Dissociative Experiences Scale (DES), and the Beck Depression Inventory (BDI), by interviewing psychiatrists and a clinic psychologist, and the subjects were allowed to fill them in the testing room. Self-reported scales were filled in the test room by the patients and were evaluated diagnosis-blind by the clinic psychologist, after all the data were integrated by the three psychiatrists. Patients suffering from a concurrent mental illness other than TTM or SP were excluded. The study protocol conformed to the Declaration of Helsinki; all patients were fully informed and signed consent forms. This study was approved by the Clinical Research Ethics Committee of Üsküdar University.

\section{Screening tools}

\section{Sociodemographic data sheet}

Data related to age, sex, education, and marital status; bodily areas of TTM and SP; and family history of TTM, SP, and other psychiatric illnesses were collected. Through clinical interviews, patients were evaluated in terms of the presence of comorbid psychiatric disorders.

\section{Structured clinical interview for DSM Axis I disorders}

It was for Turkish sample. ${ }^{27}$

\section{List of traumatic events}

It includes 16 traumatic life events prepared by the researcher in order to determine the traumatic events to which participants were exposed throughout their lives.

\section{Traumatic Stress Symptoms Scale}

TSSS was used in order to measure PTSD. It is developed by Başoğlu et al and reliability and validity studies were performed. ${ }^{28}$ It includes 23 items, and it is a four-item Likert-type scale by which people evaluate themselves for the past 1 month. Each item is scored between 0 and 3, and the total scores are obtained by summing up the scores of each item. The first 17 items question symptoms of PTSD specified in DSM-IV, and the last six items question depressive symptoms. A total score of 25 or more for the first 17 items indicates a possible diagnosis of PTSD. The cutoff point of the scale is 38 when taking all the items into consideration, 25 when taking PTSD items into consideration, and 8 when taking depression items into consideration. Başoğlu et al has reported that sensitivity and specificity for PTSD is $81 \%$.

\section{Dissociative Experiences Scale}

To determine dissociative experiences of individuals, the DES with 28 items was used. Each item of the scale is scored between 0 and 100, and the average of the scores is taken. A score above 30 suggests a diagnosis of dissociative disorder. This self-report scale has been designed by Bernstein et al to determine dissociative experiences. ${ }^{29}$ Validity and reliability studies for the Turkish version have been conducted by Şar et al. ${ }^{30}$

\section{Beck Depression Inventory}

This scale has been designed by Beck to measure depression severity. ${ }^{31}$ Validity and reliability studies for the Turkish version have been conducted by Hisli. ${ }^{32}$ It is a Likert-type scale consisting of 21 items, and each item is scored between 0 and 3. Cutoff point for Turkish version is 17.

\section{Statistical analysis}

Statistics Package for Social Sciences (SPSS) 15.0 program was used for statistical evaluation. First, data were calculated as percentages and means, and presented as descriptive statistics. One-way analysis of variance (ANOVA) and chi-square tests were used in evaluating the difference between the three groups' averages. The relationship between sociodemographic variables and clinical scale scores were investigated by Pearson's correlation test. In the evaluation of all data, the statistical significance was designed as $P<0.05$ confidence interval.

\section{Results}

The study included 104 subjects in three groups. Twenty-three of the subjects were suffering from TTM, 44 from SP, and 37 were healthy controls. The mean ages of the TTM, SP, and control groups were $32.74 \pm 9.12,31.91 \pm 9.27$, and $30.7 \pm 7.32$, respectively. Female patients were more than male patients in all groups as $78.3 \%(\mathrm{n}=18)$ in the TTM group, $75 \%(\mathrm{n}=33)$ in the SP group, and $64.9 \%(\mathrm{n}=24)$ in the control group were females. The study groups did not differ statistically significant in terms of age, sex, and marital status. TTM and SP groups did not differ significantly in terms of illness duration. Also, the groups did not differ significantly in terms of education level, family history of psychiatric illness, and family history of TTM or SP. Some demographic and clinical characteristics and statistical significance levels are shown in Table 1. 
Table I The sociodemographic characteristics of the groups

\begin{tabular}{|c|c|c|c|c|}
\hline & TTM $(n=23)$ & SP $(n=44)$ & Control $(n=37)$ & $P$-value \\
\hline Age (year) (mean $\pm S D)$ & $32.74 \pm 9$ & $31.91 \pm 9$ & $30.7 \pm 7$ & 0.61 \\
\hline \multicolumn{5}{|l|}{$\operatorname{Sex}(n, \%)$} \\
\hline Male & $5(21.7 \%)$ & II (25\%) & & \\
\hline Female & $18(78.3 \%)$ & $33(75 \%)$ & $24(64.9 \%)$ & \\
\hline \multicolumn{5}{|l|}{ Marital status (n, \%) } \\
\hline Single & $12(52.2 \%)$ & $19(43.2 \%)$ & 19 (5I.4\%) & 0.94 \\
\hline Married & $10(43.5 \%)$ & $22(50 \%)$ & $16(43.2 \%)$ & \\
\hline Widowed & I (4.3\%) & $3(6.8 \%)$ & $2(5.4 \%)$ & \\
\hline \multicolumn{5}{|l|}{ Family history of psychiatric illness } \\
\hline No & 7 (30.4\%) & $20(45.5 \%)$ & 31 (83.8\%) & 0.01 \\
\hline Yes & $16(69.6 \%)$ & $24(54.5 \%)$ & $6(16.2 \%)$ & \\
\hline \multicolumn{5}{|l|}{ Family history of TTM } \\
\hline No & $15(65.2 \%)$ & $38(86.4 \%)$ & & 0.01 \\
\hline Yes & $8(34.8 \%)$ & $6(13.6 \%)$ & - & \\
\hline \multicolumn{5}{|l|}{ Family history of SP } \\
\hline No & $7(69.6 \%)$ & $22(50 \%)$ & $36(97.3 \%)$ & 0.01 \\
\hline Yes & $7(30.4 \%)$ & $22(50 \%)$ & $\mathrm{I}(2.7 \%)$ & \\
\hline Illness duration (year) (mean \pm SD) & $14.83 \pm 9.2$ & $13.57 \pm 7.8$ & - & 0.58 \\
\hline
\end{tabular}

Note: Bold values denote $p<0.05$.

Abbreviations: TTM, trichotillomania; SP, skin picking.

Family history of TTM in TTM and SP groups were $34.8 \%(n=8)$ and $13.6 \%(n=6)$, respectively. A statistically significant difference was observed between families of the three groups in terms of TTM $(P<0.01)$. In $30.4 \%(n=7)$ of the families of the patients with TTM and in $50 \%(\mathrm{n}=22)$ of the families of the patients with SP, SP disorder was found. The difference was statistically significant between families of the three groups in terms of SP $(P<0.01)$.

The bodily areas of TTM are as $4.3 \%(\mathrm{n}=1)$ of the patients with TTM were pulling out chest hair, $8.7 \%(\mathrm{n}=2)$ only eyebrows, $8.7 \%(n=2)$ eyebrows and eyelashes, $4.3 \%(n=1)$ hair, eyebrows, and eyelashes, and $74 \%(\mathrm{n}=17)$ only scalp hair. The bodily areas of SP are as $18.2 \%(n=8)$ of the SP group were picking only lips, $4.5 \%(\mathrm{n}=2)$ intraoral picking and finger edges, $2.3 \%(\mathrm{n}=1)$ heels, $13.6 \%(\mathrm{n}=6)$ lips and finger edges, $36.4 \%(\mathrm{n}=16)$ finger edges, $2.3 \%(\mathrm{n}=1)$ general, and $11.4 \%(\mathrm{n}=5)$ face (Tables 2 and 3$)$.

There was no statistical significance between the three groups in terms of DES scores $(P=0.07)$. But BDI and TSSS scores differ significantly between the three groups $(P=0.02$ and $P=0.03$, respectively). The difference between BDI

Table 2 Symptom areas in patients with trichotillomania

\begin{tabular}{ll}
\hline Trichotillomania patients & Number \\
\cline { 2 - 2 } Areas & $\mathbf{n}(\%)$ \\
\hline Hair & $17(74)$ \\
Hair + eyebrows + eyelashes & $\mathrm{I}(4.3)$ \\
Eyebrows + eyelashes & $2(8.7)$ \\
Eyebrows & $2(8.7)$ \\
Chest hair & $\mathrm{I}(4.3)$ \\
\hline
\end{tabular}

scores originates from TTM and control groups $(P=0.03)$ and $\mathrm{SP}$ and control groups $(P=0.01)$. The clinical scale scores of the three groups are given in Table 4.

The mean number of reported traumatic life events was $4.0 \pm 3.1$ in the TTM group, $2.9 \pm 2.1$ in the SP group, and $2.5 \pm 1.4$ in the control group $(P=0.04)$. TTM and SP groups did not differ significantly in a number of traumatic life events $(P=0.15)$.

There was no statistically significant difference between the three groups in terms of the types of trauma such as natural disasters $(P=0.93)$, fire explosion $(P=0.47)$, traffic accident $(P=0.28)$, physically attacked $(P=0.21)$, sexual assault $(P=0.23)$, being in war $(P=0.17)$, exposure to torture and other ill-treatment $(P=0.25)$, death incidents such as murder-suicide $(P=0.82)$, unexpected serious illness of a loved one $(P=0.17)$, unexpected sudden death of a loved one $(P=0.72)$, sudden unexpected separation from a loved one $(P=0.89)$, domestic violence $(P=0.16)$, serious economic difficulties $(P=0.29)$, and accidents at work $(P=0.17)$. The

Table 3 Symptom areas in patients with skin picking disorder

\begin{tabular}{ll}
\hline Skin picking patients & Number \\
\cline { 1 - 2 } Areas & $\mathbf{n}(\%)$ \\
\hline Lips & $8(18.2)$ \\
Lips + finger edges & $6(13.6)$ \\
Finger edges & $16(36.4)$ \\
Intraoral + finger edges & $2(4.5)$ \\
Heels & $\mathrm{I}(2.3)$ \\
General & $\mathrm{I}(2.3)$ \\
Face & $5(11.4)$ \\
\hline
\end{tabular}


Table 4 The clinical scale scores of the three groups

\begin{tabular}{lllll}
\hline & TTM $(\mathbf{n}=\mathbf{2 3})$ & $\mathbf{S P}(\mathbf{n}=\mathbf{4 4})$ & Control $(\mathbf{n}=\mathbf{3 7})$ & $\mathbf{P}$-value \\
\hline DES (mean \pm SD) & $16.91 \pm 12$ & $13.18 \pm 8.5$ & $11.03 \pm 7.2$ & 0.07 \\
BDI (mean \pm SD) & $16.3 \pm 10$ & $15.98 \pm 10$ & $9.5 \pm 8$ & $\mathbf{0 . 0 1}$ \\
TSSS (mean \pm SD) & $20.65 \pm 13$ & $17.8 \pm 15$ & $11.35 \pm 11$ & $\mathbf{0 . 0 2}$ \\
Number of traumatic life events (mean $\pm S D)$ & $4.0 \pm 3.1$ & $2.9 \pm 2.1$ & $2.5 \pm 1.4$ & $\mathbf{0 . 0 4}$ \\
\hline
\end{tabular}

Note: Bold value denotes $p<0.05$.

Abbreviations: TTM, trichotillomania; SP, skin picking; DES, Dissociative Experiences Scale; BDI, Beck Depression Inventory; TSSS, Traumatic Stress Symptoms Scale; SD, standard deviation.

difference between the three groups in terms of bad and negative events in childhood (neglect, abuse, extreme violence, sexual harassment, and intercourse $=$ childhood traumatic experiences) was statistically significant $(P=0.01)$. Childhood traumatic experiences in terms of the difference are due to the TTM group (Figure 1).

Pearson's correlation test was applied to sociodemographic data and clinical scale score variables of groups.

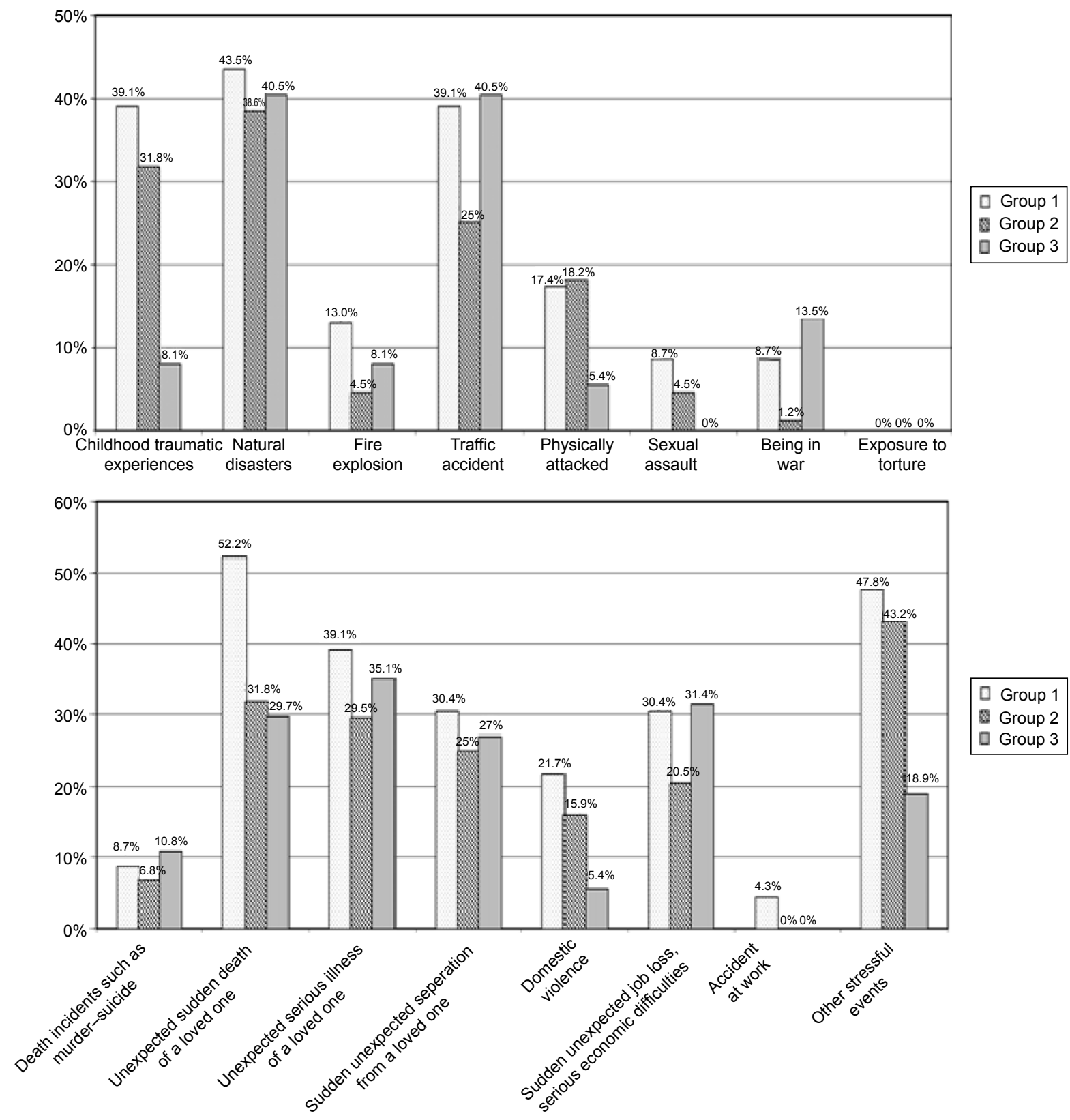

Figure I Distribution of groups in traumatic life events.

Notes: Group I, TTM group; Group 2, SP group; Group 3, healthy group.

Abbreviations: TTM, trichotillomania; SP, skin picking. 
A positive correlation was found between age and DES ( $P=0.02, r=-0.29)$, education and DES $(P<0.01, r=-0.29)$, illness duration and DES $(P=0.02, r=-0.28)$, comorbid illness and TSSS scores $(P=0.02, r=+0.27)$, DES and BDI scores $(P<0.01, r=+0.53)$, and BDI and TSSS scores $(P<0.01$, $r=+0.73)$. The number of traumatic events was negatively correlated with education $(P<0.01, r=-0.31)$ and positively correlated with comorbid psychiatric illness $(P<0.01$, $r=+0.27)$, DES score $(P<0.01, r=+0.53)$, and BDI scores $(P<0.01, r=+0.73)$. In all, $30.5 \%(\mathrm{n}=7)$ of the TTM group and $22.8 \%(\mathrm{n}=10)$ of the SP group had a diagnosis of PTSD. The average TSSS score of the PTSD diagnosed total group was $36.14 \pm 7.5$. A total of $80.8 \%$ of the total group ( $n=84$ ) got a score of lesser than 25 points and $19.2 \%(n=20)$ got a score above 25 points in TSSS. PTSD positive and negative groups were compared to chi-square test for sociodemographic data and with independent $t$-test for parametric variables. There was no statistically significant difference observed between the sociodemographic and disease-related variables of PTSD and non-PTSD subjects in the TTM group. In the SP group, there was a difference only in terms of BDI scores between PTSD and non-PTSD subjects $(P<0.01)$. The group with TSSS score over 25 points had a correlation with BDI scores $(P<0.01, r=+0.84)$. In the PTSD negative group, there was a correlation between education level $(P<0.01, r=-0.45)$, DES $(P \leq 0.01, r=+0.32)$, and BDI scores $(P \leq 0.01, r=+0.49)$.

There were a total of six subjects with a DES score of $\geq 30$ in this study. In total, $17.4 \%(n=4)$ of the TTM group and $4.5 \%(n=2)$ of the SP group were diagnosed with dissociative disorder.

\section{Discussion}

This study aimed to search for the relationship of psychological trauma with TTM and SP. A secondary aim was to investigate the presence of dissociative symptoms with TTM or SP.

The results of the present study suggest that $34.8 \%$ of patients with TTM had TTM history in their families. Previous studies have reported $22.7 \% \%^{33}$ and $25.5 \%{ }^{26}$ TTM in the families of patients with TTM. In the SP group, we found $50 \%$ families with history of TTM. Again, in previous studies, $28.3 \%{ }^{26}$ and $43 \%{ }^{19}$ of the first-degree relatives of the patients with SP disorder has been found to have SP disorder. Although the number of publications is limited, high frequency of positive family history suggests that genetic transmission may be important in the etiology of TTM and SP. ${ }^{34-36}$ Average duration of illness was found to be $14.83 \pm 9.2$ years in the TTM group and $13.57 \pm 7.8$ years in the SP group; it can be said that the average age of onset of TTM and SP was approximately. ${ }^{17,18}$ In literature, age at disease onset has been defined bimodal as age of childhood and adolescence. ${ }^{33,37}$ In late onset, more severe course of the disease, greater comorbidity and severity of symptoms, and treatment resistance are observed. ${ }^{38}$

In our study, BDI scores in TTM and SP groups were significantly higher than healthy subjects. Although BDI scores are not sufficient alone to diagnose major depressive disorder, it refers to depressive tendency. Also in previous studies, risk of developing comorbid mood disorders in patients with TTM has been reported to be increased. ${ }^{33,39}$ History of traumatic events in childhood, such as neglect, abuse, extreme violence, sexual harassment, or intercourse, and history of any other stressful life events did differ significantly among TTM, SP, and control groups. There was a statistically significant difference in both TTM and SP groups in terms of traumatic and negative events in childhood (neglect, abuse, extreme violence, sexual harassment, and intercourse) when compared to healthy subjects. In a study, childhood sexual trauma has been found as $25.8 \%$ and childhood physical abuse as $20.6 \%$ in subjects with TTM. ${ }^{6}$ Gershuny et al reported that the childhood trauma was significantly higher in OCD and TTM groups than in healthy subjects. In this study, emotional neglect was found to be higher in both OCD and TTM groups than in the control group. Physical abuse score in the TTM group was significantly higher than that in healthy controls. ${ }^{6}$ Boughn and Holdom reported history of violence during the onset of TTM symptoms in $86 \%$ of 44 female patients with TTM. ${ }^{20}$ These studies suggested that childhood traumas may be related to the development of TTM cases. In our study, $30.5 \%$ of the TTM group and $22.8 \%$ of the SP group were diagnosed with PTSD using TSSS.

In this study, we classified individuals with DES score of $\geq 30$ as possible cases of dissociative disorder, and $17.4 \%$ of the TTM group and $4.5 \%$ of the SP group were in this group. Congruent with our results, in the study by Lochner et al the frequency of individuals with a DES score of 30 and more was reported as $18.8 \%$ in the TTM group. ${ }^{15}$ In our study and in the study by Lochner et al DES scores were about the same in the TTM group. In studies with Turkish population, the mean DES score was found to be 17.88 and 7.67 in psychiatry inpatients and general population, respectively. ${ }^{40,41}$ A study investigating the relationship of dissociation and TTM/SP revealed that approximately one in three of the patients with SP was feeling mesmerized during picking behavior. ${ }^{24,25}$ Another study reported that $21.3 \%$ of the patients with TTM reported depersonalization during hair pulling behavior. ${ }^{26}$ 
In our study, we found negative correlation between DES and TSSS scores and duration of TTM and SP. In the study by Gershuny et al increased duration and number of hairs pulled were negatively correlated with the presence of PTSD symptoms. ${ }^{6}$ The reason for the negative correlation of severity of PTSD and TTM may be speculated as developing TTM symptoms helps the patient to cope with intrusive thoughts related to trauma. If TTM is taken into account as a coping mechanism, it may contribute to prevention of PTSD development. The person suffering from the traumatic material may sooth the anxiety by focusing on hair pulling.

The diagnosis of anxiety disorders has encountered various changes in the recently released DSM-5. ${ }^{13}$ One is the addition of the dissociative subtype of PTSD. The dissociative subtype is not a subset of the core PTSD symptoms, but rather indicates a class of PTSD characterized by additional comorbid symptoms of derealization and/or depersonalization.

Those individuals set a dissociative group who were distinct from those with high PTSD severity and no dissociation and those with low PTSD severity and no dissociation. ${ }^{42}$

Symptoms of dissociation are important clinical phenomena that may become a target of treatment in cases of TTM with a history of childhood trauma. Dissociative symptoms may also interfere with TTM treatment as dissociation may interfere with the processing of trauma memories and related emotions and cognitions in trauma-focused therapies.

The dissociative symptoms seen in TTM and SP may be associated with a distinct etiology, biology, course, and treatment response. For example, individuals with the dissociative subtype may have different genetic vulnerabilities than individuals who do not dissociate. Providing a clear definition of the TTM and SP comorbidity with dissociative symptomatology would help to understand genetic, neurobiological, cognitive, and psychosocial mechanisms of TTM and SP.

The most obvious limitation of our study is the usage of three self-reported scales (list of traumatic events, TSSS, and DES). The reliability of the scales filled out without a clinician's intervention is lower than that of structured forms. As the small size of the current study is the major limitation of this study, we cannot come to a conclusion that TTM serves a dissociative or anxiety-relieving function. The study group consisted of individuals who were seeking treatment for TTM or SP. Another limitation of the study is the increased probability of a Type I error associated with multiple $t$-tests. This is another limitation of the study due to the probability of symptoms of avoidance in individuals with a comorbidity of PTSD; we can speculate that they did not seek treatment and did not participate in the study.

\section{Conclusion}

In this study, we included two self-harming groups, SP and TTM, to get information about the relation of self-harming disorders and past traumas. Dissociation, PTSD, and depression mean scores of TTM and SP groups were not statistically different from one another. Although two self-harming groups did not differ significantly from each other in depression or PTSD scores, they were both significantly differing from the healthy control group. We can conclude that trauma and PTSD may play a role in etiology of both TTM and SP. PTSD symptoms reduce with the prolonged TTM and SP illness duration. The reason for the negative correlation of severity of PTSD and TTM may be speculated as developing TTM or SP symptoms helps the patient to cope with intrusive thoughts related to trauma. Future longitudinal research must focus on whether trauma and PTSD or TTM and SP precede the development of mental disorder.

\section{Disclosure}

The authors report no conflicts of interest in this work.

\section{References}

1. Chamberlain SR, Fineberg NA, Blackwell AD, Clark L, Robbins TW, Sahakian BJ. A neuropsychological comparison of obsessive-compulsive disorder and trichotillomania. Neuropsychologia. 2007;45(4):654-662.

2. Duke DC, Keeley ML, Geffken GR, Stroch EA. Trichotillomania: a current review. Clin Psychol Rev. 2010;30(2):181-193.

3. Flessner CA, Busch AM, Heideman PW, Woods DW. Acceptanceenhanced behavior therapy (AEBT) for trichotillomani and chronic skin picking: exploring the effects of component sequencing. Behav Modif. 2008;32(5):579-594.

4. World Health Organization. The ICD-10 Classification of Mental and Behavioural Disorders. Clinical Descriptions and Diagnostic Guidelines. Geneva: WHO; 1992.

5. Keuthen NJ, Stein DJ, Christenson GA. Help for Hair Pullers: Understanding and Coping with Trichotillomania. Oakland: New Harbinger Publications; 2001.

6. Gershuny BS, Baer L, Radomsky AS, Wilson KA, Jenike MA. Connections among symptoms of obsessive-compulsive disorder and posttraumatic stress disorder: a case series. Behav Res Ther. 2003;41(9):1029-1041.

7. Shoenfeld N, Rosenberg O, Kotler M, Dannon PN. Trichotillomania: pathopsychology theories and treatment possibilities. Isr Med Assoc J. 2012;14(2):125-129.

8. Baer L, Osgood-Hynes D, Minichiello WE. Trichotillomania. In: Ammerman RT, Last CG, Hersen M, editors. Handbook of Prescriptive Treatments for Children and Adolescents. Needham Heights, MA: Allyn \& Bacon; 1999:277-292.

9. Arnold LM, Auchenbach MB, McElroy SL. Psychogenic excoriation. Clinical features, proposed diagnostic criteria, epidemiology and approaches to treatment. CNS Drugs. 2001;15(5):351-359.

10. Bohne A, Wilhelm S, Keuthen NJ, Baer L, Jenike ME. Skin picking in German students. Prevalence, phenomenology, and associated characteristics. Behav Modif. 2002;26(3):320-339. 
11. Hayes SL, Storch EA, Berlanga L. Skin picking behaviors: an examination of the prevalence and severity in a community sample. $J$ Anxiety Disord. 2009;23(3):314-319.

12. American Psychiatric Association. Diagnostic and Statistical Manual of Mental Disorders. 4th ed. Washington, DC: American Psychiatric Association; 1994.

13. American Psychiatric Association. Diagnostic and Statistical Manual of Mental Disorders. 5th ed. Washington, DC: American Psychiatric Association; 2013.

14. Shusterman A, Feld L, Baer L, Keuthen N. Affective regulation in trichotillomania: evidence from a large-scale internet survey. Behav Res Ther. 2009;47(8):637-644.

15. Lochner C, du Toit PL, Zungu-Dirwayi N, Marais A, van Kradenburg J, Seedat S. Childhood trauma in obsessive-compulsive disorder, trichotillomania, and controls. Depress Anxiety. 2002;15(2):66-68.

16. Diefenbach GJ, Reitnam D, Williamson DA. Trichotillomania: a challenge to research and practice. Clin Psychol Rev. 2000;20:289-309.

17. WhiteKress VE, Kelly BL, McCormick LJ. Trichotillomania: assessment, diagnosis, and treatment. J Couns Dev. 2004;82(2):185-190.

18. Bordnick PS, Thyer BA, Ritchie BW. Feather picking disorder and trichotillomania: an avian model of human psychopathology. J Behav Ther Exp Psychiatry. 1994;25:189-196.

19. Neziroglu F, Rabinowitz D, Breytman A, Jacofsky M. Skin picking phenomenology and severity comparison. Prim Care Companion J Clin Psychiatry. 2008;10(4):306-312.

20. Boughn S, Holdom JAJ. The relationship of violence and trichotillomania. J Nurs Scholarsh. 2003;35:165-170.

21. Favaro A, Ferrara S, Santonastaso P. Self-injurious behavior in a community sample of young women: relationship with childhood abuse and other types of self-damaging behaviors. J Clin Psychiatry. 2007; 68(1):122-131.

22. Lochner C, Seedat S, Hemmings SMJ, Kinnear CJ, Corfield VA, Niehaus DJHR. Dissociative experiences in obsessive-compulsive disorder and trichotillomania: clinical and genetic findings. Compr Psychiatry. 2004;45:384-391.

23. Gershuny BS, Keuthen NJ, Gentes EL, Russo AR, Emmott EC, Jameson M. Current posttraumatic stress disorder and history of trauma in trichotillomania. J Clin Psychol. 2006;62(12):1521-1529.

24. Sonarrason I, Smari J, Olafsson RP. Emotion regulation in pathological skin picking: findings from a non-treatment seeking sample. J Behav Ther Exp Psychiatry. 2010;41:238-245.

25. Wilhelm S, Keuthen NJ, Deckersbach T, Engelhard IM, Forker AE, Bear L. Self-injurious skin picking: clinical characteristics and comorbidity. J Clin Psychiatry. 1999;60:454-459.

26. du Toit PL, van Kradenburg J, Niehaus DJH, Stein DJ. Characteristics and phenomenology of hair-pulling: an exploration of subtypes. Compr Psychiatry. 2001;42:247-256.

27. Özkürkçügil A, Aydemir Ö, Yıldız M, Danacı EA, Köroğlu E. Reliability and validity of the Turkish version of the Structured Clinical Interview for DSM-IV [DSM-IV eksen I bozuklukları için yapılandırılmış klinik görüşmenin türkçeye uyarlanması ve güvenilirlik çalışması]. İlaç ve Tedavi Dergisi. 1999;12:233-236.
28. Başoğlu M, Şalcıoğlu E, Livanou MA. Study of the validity of a screening instrument for traumatic stress in earthquake survivors in Turkey. J Trauma Stress. 2001;14:491-509.

29. Bernstein EM, Putnam FW, Frank W. Development, reliability and validity of a dissociation scale. J Nerv Ment Disord. 1986;47:285-293.

30. Şar V, Kundakçı T, Kızıltan E. Disosiyatif Yaşantılar Ölçeği’nin (DES-II) geçerlik ve güvenirliği. [Dissociative Experiences Scale (DES-II) reliability and validity]. Ulusal Psikiyatri Kongresi, Antalya; 1997:33. Turkish.

31. Beck AT, Ward CH, Mendelson M, Mock J, Erbaugh J. An inventory for measuring depression. Arch Gen Psychiatry. 1961;4:561-571.

32. Hisli N. The reliability and validity analysis of the Turkish version of Beck Depression Inventory in university students. [Beck Depresyon Envanterinin üniversite öğrencileri için geçerliliği, güvenirliği]. Psikoloji Dergisi. 1989;7:3-13.

33. Schlosser S, Black DW, Blum N, Goldstein RB. The demography, phenomenology, and family history of 22 persons with compulsive hair pulling. Annals Clin Psychiatry. 1994;6:147-152.

34. Odlaug BL, Grant JE. Pathologic skin picking. In: Grant JE, Stein DJ, Woods DW, Keuthen NJ, editors. Trichotillomania, Skin Picking, and Other Body-Focused Repetitive Behaviors. Washington, DC: American Psychiatric Publishing; 2012:21-41.

35. Greer JM, Capecchi MR. Hoxb8 is required for normal grooming behavior in mice. Neuron. 2000;33(1):23-34.

36. Zuchner S, Cuccaro ML, Tran-Viet KN, Cope H, Krishnan RR, PericakVance MA. SLITRK1mutations in trichotillomania. Mol Psychiatry. 2006;11:887-889.

37. Mansueto CS, Rogers KE. Trichotillomania: Epidemiology and Clinical Characteristics. Clinical Manual for the Treatment of Trichotillomania, Skin-picking, and Other Stereotypic Disorders. Arlington, VA: American Psychiatric Publishing; 2011.

38. Lewin AB, Piacentini J, Flessner CA, Woods DW, Franklin ME, Keuthen NJ. Depression, anxiety, and functional impairment in children with trichotillomania. Depress Anxiety. 2009;26(6):521-527.

39. Duke DC, Bodzin DK, Tavares P, Geffken GR, Storch EA. The phenomenology of hair pulling in a community sample. J Anxiety Disord. 2009;23(8):1118-1125.

40. Tutkun H, Sar V, Yargic LI, Ozpulat T, Yanık M, Kizıltan E. Frequency of dissociative disorders among psychiatric inpatients in a Turkish University Clinic. Am J Psychiatry. 1998;155:800-805.

41. Akyuz G, Dogan O, Sar V, Yargic LI, Tutkun H. Frequency of dissociative identity disorder in the general population in Turkey. Compr Psychiatry. 1999;40:151-159.

42. Stein DJ, Koenen KC, Friedman MJ, Hill E, McLaughlin KA, Petukhova M. Dissociation in posttraumatic stress disorder: evidence from the world mental health surveys. Biol Psychiatry. 2013; $73: 302-312$.
Neuropsychiatric Disease and Treatment

\section{Publish your work in this journal}

Neuropsychiatric Disease and Treatment is an international, peerreviewed journal of clinical therapeutics and pharmacology focusing on concise rapid reporting of clinical or pre-clinical studies on a range of neuropsychiatric and neurological disorders. This journal is indexed on PubMed Central, the 'PsycINFO' database and CAS,
Dovepress

and is the official journal of The International Neuropsychiatric Association (INA). The manuscript management system is completely online and includes a very quick and fair peer-review system, which is all easy to use. Visit http://www.dovepress.com/testimonials.php to read real quotes from published authors. 